\title{
Cerambycidae (Coleoptera) do Museu de Zoologia da Universidade Estadual de Feira de Santana, Bahia
}

\author{
Ubirajara R. Martins ${ }^{1,3}$ \& Maria Helena M. Galileo ${ }^{2,3}$ \\ 1. Museu de Zoologia, Universidade de São Paulo, Caixa Postal 42594, 04218-970, São Paulo, SP, Brasil. (urmsouza@usp.br) \\ 2. Museu de Ciências Naturais, Fundação Zoobotânica do Rio Grande do Sul. Rua Dr. Salvador França, 1427, 90690-000, Porto Alegre, RS, Brasil \\ 3. Pesquisador do CNPq.
}

\begin{abstract}
Cerambycidae (Coleoptera) from Museu de Zoologia of Universidade Estadual de Feira de Santana, Bahia. New species in Cerambycinae described from Brazil, Piauí: Compsibidion paragraphycum sp. nov. (Neoibidionini). New species in Lamiinae - from Piauí: Trichohippopsis vestita sp. nov. (Agapanthiini); Oncioderes piauiensis sp. nov. (Onciderini); Cotycicuiara caracolensis sp. nov. (Desmiphorini); Xenofrea peculiaris sp. nov. (Xenofreini); Mariliana bellula sp. nov. (Hemilophini); - from Paraíba: Ataxia arenaria sp. nov. (Pteropliini); Dadoychus atrus sp. nov. (Hemilophini). New records in Cerambycinae from Piauí: Methia longipennis Martins \& Galileo, 1997 (Methiini); Tropidion sipolisi (Gounelle, 1909), Compsibidion decoratum (Gounelle, 1909), Cycnidolon obliquum Martins, 1969 (Neoibidionini); - from Ceará: Paranyssicus conspicillatus (Erichson, 1847) (Elaphidiini); Aglaoschema collorata (Napp, 1993) (Compsocerini); - from Bahia: Stizocera phtisica Gounelle, 1909 (Elaphidiini). New records in Lamiinae from Piauí: Dolichosybra tubericollis Breuning, 1942 (Apomecynini); Ceiupaba lineata Martins \& Galileo, 1998, Cicuiara striata (Bates, 1866), Desmiphora pallida Bates, 1874 (Desmiphorini); Nesozineus apharus Galileo \& Martins, 1996, Psapharochrus nigrovittatus (Zajciw, 1969) (Acanthoderini); - from Ceará: Trichohippopsis rufula Breuning, 1958 (Agapanthiini); Ataxia parva Galileo \& Martins, 2011 (Pteropliini); Desmiphora cirrosa Erichson, 1847 (Desmiphorini); - from Paraíba: Eudesmus rubefactus Bates, 1865 (Onciderini); Laraesima ochreoapicalis Breuning, 1973 (Compsosomatini); Psapharochrus itatiayensis (Melzer, 1935) (Acanthoderini); - from Bahia: Brasiliosoma tibiale (Breuning, 1948) (Compsosomatini); Adesmus hemispilus (Germar, 1821) (Hemilophini).
\end{abstract}

KEYWORDS. Brazil, Cerambycinae, Lamiinae, new records, new species.

RESUMO. Novas espécies em Cerambycinae são descritas do Brasil, Piauí: Compsibidion paragraphycum sp. nov. (Neoibidionini). Em Lamiinae, - do Piaú: Trichohippopsis vestita sp. nov. (Agapanthiini); Oncioderes piauiensis sp. nov. (Onciderini); Cotycicuiara caracolensis sp. nov. (Desmiphorini); Xenofrea peculiaris sp. nov. (Xenofreini); Mariliana bellula sp. nov. (Hemilophini); - da Paraíba: Ataxia arenaria sp. nov. (Pteropliini); Dadoychus atrus sp. nov. (Hemilophini). Novos registros em Cerambycinae para o Piauí: Methia longipennis Martins, 1997 (Methiini); Tropidion sipolisi (Gounelle, 1909), Compsibidion decoratum (Gounelle, 1909), Cycnidolon obliquum Martins, 1969 (Neoibidionini); - para o Ceará: Paranyssicus conspicillatus (Erichson, 1847) (Elaphidiini); Aglaoschema collorata (Napp, 1993) (Compsocerini); - para a Bahia: Stizocera phtisica Gounelle, 1909 (Elaphidiini). Novos registros em Lamiinae para o Piaú: Dolichosybra tubericollis Breuning, 1942 (Apomecynini); Ceiupaba lineata Martins \& Galileo, 1998, Cicuiara striata (Bates, 1866), Desmiphora pallida Bates, 1874 (Desmiphorini); Nesozineus apharus Galileo \& Martins, 1996, Psapharochrus nigrovittatus (Zajciw, 1969) (Acanthoderini); - para o Ceará: Trichohippopsis rufula Breuning, 1958 (Agapanthiini); Ataxia parva Galileo \& Martins, 2011 (Pteropliini); Desmiphora cirrosa Erichson, 1847 (Desmiphorini); - para a Paraíba: Eudesmus rubefactus Bates, 1865 (Onciderini); Laraesima ochreoapicalis Breuning, 1973 (Compsosomatini); Psapharochrus itatiayensis (Melzer, 1935) (Acanthoderini); - para a Bahia: Brasiliosoma tibialis (Breuning, 1948) (Compsosomatini); Adesmus hemispilus (Germar, 1821) (Hemilophini).

PALAVRAS-CHAVE. Brasil, Cerambycinae, Lamiinae, novos registros, novas espécies.

Os cerambicídeos do nordeste do Brasil ainda são poucos conhecidos apesar dos artigos publicados sobre a fauna da Paraíba (ZAJciw, 1965), do Ceará (ZAJciw, 1966), do Maranhão (ZAJCIw, 1967), de Alagoas, Pernambuco (inclusive da ilha de Fernando de Noronha), Rio Grande do Norte e Piauí (ZAJciw, 1968a,b). Mais recentemente, MARTINS et al. (2009a,b; 2011) trataram de representantes do Maranhão.

O material recebido da coleção do Museu de Zoologia da Universidade Estadual de Feira de Santana, Bahia, nos permitiu apresentar 21 novos registros para os estados do nordeste do Brasil: 10 registros do Piauí, 5 do Ceará, 3 da Paraíba e 3 registros da Bahia.

Descrevem-se ainda oito espécies novas, uma delas em Neoibidionini (Cerambycinae), gênero Compsibidion Thomson, 1864. As demais pertencem às tribos de Lamiinae: Agapanthiini, Desmiphorini, Hemilophini, Onciderini, Pteropliini e Xenofreini.

O material estudado pertence ao Museu de Zoologia da Universidade Estadual de Feira de Santana, Bahia.

\section{RESULTADOS E DISCUSSÃO}

\section{CERAMBYCINAE Elaphidiini}

\section{Paranyssicus conspicillatus (Erichson, 1847)}

Mallocera conspicillata ERICHSON, 1847:141.

Nyssicus conspicillatus; GounELle, 1909b:304; MonNÉ, 2005a:229 (cat.). Paranyssicus conspicillatus; MarTins, 2005:76, figs. 81, 82; MONNÉ \& HOVORE, 2006:70 (checklist).

Anoplomerus quadriguttatus BuQuet, 1860:627; TAVAKILIAN, 1991:443 (sin.). Nyssicus quadrinus Bates, 1870:271; Gounelle, 1909b:304 (sin.).

Material examinado. BRASIL, Ceará: Crato (Chapada do Araripe, $\left.7^{\circ} 12,548^{\prime} \mathrm{S}, 39^{\circ} 35,839^{\prime} \mathrm{W}, 929 \mathrm{~m}\right), \partial^{\lambda}$, A. M. Silva-Neto, M. $\mathrm{X}$. Araújo \& E. Menezes col. (novo registro).

\section{Stizocera phtisica Gounelle, 1909}

Stizocera phtisica Gounelle, 1909a:643; Monné, 2005a:256 (cat.).

Nesostizocera phtisica; MARTINS \& NAPP, 1983:88.

Stizocera phtisica; Lingafelter, 1998:93. 
Material examinado. BRASIL, Bahia: Pindobaçu (Cachoeira da Fumaça, $10^{\circ} 28^{\prime} 43^{\prime \prime}$ S, 40¹2’27,6”W), + , 17.XII.2009, T. Zacca col. (novo registro).

\section{Neoibidionini, Tropidina}

\section{Tropidion sipolisi (Gounelle, 1909)}

Ibidion sipolisi GOUNELLE, 1909a:681.

Tropidion sipolisi; MarTins, 1968:367, figs. 205-208; MonNÉ, 2005a:343 (cat.).

Ibidion haliki Martins, 1962:301, fig. 41a.; Martins, 1968:367 (sin.).

Material examinado. BRASIL, Piauí: Caracol (Parque Nacional da Serra das Confusões, Fonte dos Bois, 4329,391'S, $\left.09^{\circ} 13,228^{\prime} \mathrm{W}, 587 \mathrm{~m}\right)$, ô,, , , 7-17.XII.2010, A. M. Silva-Neto \& M. Xavier col. (novo registro).

\section{Neoibidionina}

\section{Compsibidion decoratum (Gounelle, 1909)}

Octoplon decoratum GounelLe, 1909a:665.

Compsibidion decoratum; Martins, 1969:781, fig. 393; Monné, 2005a:347 (cat.)

Material examinado. BRASIL, Piaú: Caracol (Parque Nacional da Serra das Confusões, Fonte dos Bois, 4329,391'S, $\left.09^{\circ} 13,228^{\prime} \mathrm{W}, 587 \mathrm{~m}\right)$, J', ㅇ, 7-17.XII.2010, A. M. Silva-Neto \& M. Xavier col. (novo registro).

\section{Cycnidolon obliquum Martins, 1969}

Cycnidolon obliquum Martins, 1969:852, fig. 453; MonNÉ, 2005a:355 (cat.).

Cycnidolon unoculum; Gounelle, 1909a:668 (non Octoplon unoculum Bates, 1870).

Cycnidolon binodosum; ZaJcIw, 1967:7 (non Bates, 1870).

Material examinado. BRASIL, Piauí: Caracol (Parque Nacional da Serra das Confusões, Fonte dos Bois, 4329,391'S, $\left.09^{\circ} 13,228^{\prime} \mathrm{W}, 587 \mathrm{~m}\right)$, J', ㅇ, 7-17.XII.2010, A. M. Silva-Neto \& M. Xavier col. (novo registro).

\section{Compsibidion paragraphycum sp. nov.} (Fig. 1)

Etimologia. Latim, par = semelhante; graphycum = nome específico; alusivo à semelhança com $C$. graphicum (Thomson, 1867).

Macho. Cabeça preto-avermelhada. Lobos oculares superiores com quatro fileiras de omatídios. Escapo preto. Pedicelo preto-avermelhado. Antenômero III avermelhado e engrossado, subcilíndrico, com pedúnculo curto e carenado. Antenômero IV avermelhado, carenado, também ligeiramente engrossado, com um terço do comprimento do III. Demais flagelômeros não engrossados, com comprimentos gradualmente crescentes. Pelos internos dos flagelômeros muito esparsos.

Protórax avermelhado; partes laterais com mancha de pubescência esbranquiçada na metade posterior. Pronoto com cinco tubérculos: dois látero-anteriores, um central e dois látero-posteriores. Pubescência esbranquiçada localizada na base, entre os tubérculos látero-posteriores e junto da borda anterior do pronoto à frente dos tubérculos látero-anteriores. A pubescência não reveste o centro do pronoto, que é brilhante.

Élitros com a metade anterior avermelhada e a metade posterior preta; mancha branco-amarelada no dorso da metade anterior e faixa oblíqua brancoamarelada entre as colorações dominantes; mancha branco-amarelada apical não envolve a sutura e a margem; mancha branco-amarelada alongada junto à margem. Em cada élitro, cinco fileiras de pontos pilíferos, três dorsais e duas laterais. Extremidades elitrais com espinho longo no lado externo e espículo no lado interno.

Pro- e mesofêmures avermelhados; metafêmures pretos nos 2/3 apicais e avermelhados no terço basal. Ápice dos mesofêmures com aba interna projetada; ápice dos metafêmures com abas apicais agudas. Tíbias e tarsos avermelhados.

Esternos torácicos avermelhados. Urosternito I avermelhado; urosternitos II-V pretos.

Dimensões em mm, holótipo macho. Comprimento total, 10,3; comprimento do protórax, 2,3; maior largura do protórax, 1,6; comprimento do élitro, 6,6; largura umeral, 2,1 .

Material-tipo. Holótipo macho, BRASIL, Piauí: Caracol (Parque Nacional da Serra das Confusões, Fonte dos Bois, 4329'391'S, 09¹3'228”'W, 587 m); parátipo ㅇ, 7-17.XII.2010, A M. Silva-Neto \& M. Xavier col.

Discussão. As espécies sul-americanas de Compsibidion foram revistas recentemente por MARTINS \& GaLILEO (2007) e apresentada uma chave para espécies. Compsibidion paragraphycum sp. nov. é discriminada no item 47 junto com C. simillimum Martins, 1969. Compsibidion paragraphycum sp. nov. distingue-se de $C$. simillimum: pelo antenômero IV dos machos relativamente menos engrossado; pela pubescência do pronoto que não está organizada em uma faixa longitudinal de cada lado; pelas manchas branco-amareladas da metade anterior dos élitros mais arredondadas; pela faixa não intrometida entre as manchas; pela mancha branco-amarelada no ápice dos élitros; pelos pro- e metafêmures não escurecidos nas pontas e pelos metafềmures pretos nos $2 / 3$ apicais. Em $C$. simillimum: o antenômero IV dos machos é nitidamente engrossado; a pubescência do pronoto está organizada em duas faixas longitudinais; as manchas branco-amareladas da metade anterior dos élitros são alongadas e a faixa clara intromete-se entre as duas manchas; a mancha apical branca não existe; os pro- e mesofêmures são escurecidos no ápice e os metafêmures enegrecidos no máximo no terço apical.

\section{Methiini}

\section{Methia longipennis Martins \& Galileo, 1997}

Methia longipennis Martins \& GaliLeo, 1997:167, fig. 146; Monné, 2005a:396 (cat.). 
Material examinado. BRASIL, Piauí: Caracol (Parque

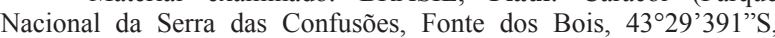
09¹3’228”W, 587 m), o, ㅇ, 7-17.XII.2010, A. M. Silva-Neto \& M. Xavier col. (novo registro).

\section{Compsocerini}

Aglaoschema collorata (Napp, 1993)

Orthoschema (Orthoschema) collorata NAPP, 1993:653, fig. 1. Aglaoschema collorata; NAPP, 1994:659; MONNÉ, 2005a:118 (cat.).

Material examinado. BRASIL, Ceará: Ubajara (Chapada de Ibiapaba, 5444,669'S, 350,214’W, 827 m), O’, 25-29.IX.2011, A. M. Silva-Neto \& F. E. Nascimento col., armadilha luminosa (novo registro).

\section{LAMIINAE}

Agapanthiini

\section{Trichohippopsis rufula Breuning, 1958}

Trichohippopsis rufula Breuning, 1958:26; Monné, 2005b:259 (cat.).

Material examinado. BRASIL, Ceará: Crato (Chapada do Araripe, $\left.7^{\circ} 12,548^{\prime} \mathrm{S}, 39^{\circ} 35,839^{\prime} \mathrm{W}, 929 \mathrm{~m}\right)$, ô', A. M. Silva-Neto, M. X. Araújo \& E. Menezes col. (novo registro)

\section{Trichohippopsis vestita sp. nov.}

(Fig. 2)

Etimologia. Latim, vestitus $=$ revestido; alusivo à indumentária do corpo.

Fêmea. Cabeça avermelhada, arredondada, mais larga que o protórax. Fronte estreita, revestida por pilosidade esbranquiçada. Tubérculos anteníferos projetados e próximos entre si. Vértice pontuado, coberto por pilosidade esbranquiçada, esparsa. Olhos grosseiramente facetados. Lobos oculares superiores com cinco fileiras de omatídios e separados entre si por distância menor que a largura de um lobo. Antenas avermelhadas; atingem as pontas dos élitros aproximadamente no ápice do antenômero IX. Escapo cilíndrico, tão longo quanto o antenômero III, provido de pelos curtos e curvos em toda a superfície. Flagelômeros com pelos bem longos no lado interno e providos de pelos curtos em toda superfície $(25 \mathrm{x})$. Antenômero XI tão longo quanto o $\mathrm{X}$, provido de pelos mais longos do que no restante da antena em toda a superfície, além dos pelos longos e esparsos. Metepisternos, metasterno e urosternitos pontuados.

Protórax avermelhado, cilíndrico, sem gibosidade lateral. Pronoto coberto por pilosidade esbranquiçada, esparsa; os pelos mais ou menos convergentes para o centro. Partes laterais do protórax com pilosidade semelhante.

Escutelo revestido por pubescência esbranquiçada, densa. Élitros avermelhados, pontuados em toda superfície; pilosidade não oblitera o tegumento, mas é mais densa sobre o friso sutural. Extremidades elitrais arredondadas.

Fêmures curtos, fusiformes. Profêmures avermelhados. Meso- e metafêmures mais enegrecidos. Pontas dos metafêmures não atingem a orla apical do urosternito I. Tíbias avermelhadas. Protíbias curvas. Mesotíbias com sulco na margem externa, muito profundo e situado próximo da extremidade.

Dimensões em mm, holótipo fêmea. Comprimento total, 9,7; comprimento do protórax, 1,5; maior largura do protórax, 1,2; comprimento do élitro, 7,0; largura umeral, 1,7 .

Material-tipo. Holótipo fêmea, BRASIL, Piauí: Caracol (Parque Nacional da Serra das Confusões, Fonte dos Bois, $43^{\circ} 29,391$ 'S, $09^{\circ} 13,228^{\prime} \mathrm{W}, 587 \mathrm{~m}$ ), , , 7-17.XII.2010, A. M. SilvaNeto \& M. Xavier col.

Discussão. Pela sutura elitral revestida por pubescência branca, densa, Trichohippopsis vestita sp. nov. assemelha-se a $T$. suturalis Martins \& Carvalho, 1983. Distingue-se: lobos oculares superiores mais largos e mais próximos; escapo sem alargamento apical; pronoto, élitros e face inferior do corpo sem regiões mais escurecidas.

\section{Apomecynini}

\section{Dolichosybra tubericollis Breuning, 1942}

Dolichosybra tubericollis BREUNING, 1942:152; MONNÉ, 2005b:299 (cat.)

Material examinado. BRASIL, Piauí, Caracol (Parque Nacional da Serra das Confusões, Fonte dos Bois, 4329,391'S 09¹3,228’W, $587 \mathrm{~m}$ ), ㅇ, 7-17.XII.2010, A. M. Silva-Neto \& M. Xavier col. (novo registro)

\section{Onciderini}

\section{Eudesmus rubefactus Bates, 1865}

Eudesmus rubefactus BATES, 1865:180; MonNÉ, 2005b:548 (cat.).

Material examinado. BRASIL, Paraíba: Areia (Reserva Pau Ferro, Brejo Paraibano, $35^{\circ} 44,507^{\prime} \mathrm{S}, 6^{\circ} 58,212^{\prime} \mathrm{W}, 567 \mathrm{~m}$ ), 우, 25 29.IX.2010, A. M. Silva-Neto \& F. E. Nascimento col., armadilha luminosa (novo registro)

\section{Oncioderes piauiensis sp. nov.} (Fig. 3)

Etimologia. Epíteto é alusivo ao estado brasileiro da localidade-tipo.

Fêmea. Tegumento corporal preto. Fronte subquadrangular revestida por pubescência esbranquiçada no meio e amarelada nos lados; pontuação não aparente. Vértice com duas pequenas manchas triangulares de pubescência castanha. Regiões atrás dos olhos com 
pubescência alaranjada. Lobos oculares superiores com seis fileiras de omatídios, tão distantes entre si quanto o dobro da largura de um lobo. Antenas atingem os ápices dos élitros aproximadamente no meio do antenômero IX. Escapo pouco e gradualmente engrossado para o ápice, coberto por pubescência acastanhada. Pedicelo e antenômero III revestidos por pubescência esbranquiçada na base e mais acastanhada para o ápice. Demais antenômeros gradualmente mais enegrecidos.

Protórax cilíndrico, mais largo do que longo. Lados do protórax com tubérculo diminuto. Pronoto com pubescência esbranquiçada no meio e mais alaranjada para os lados e pontos contrastantes pouco numerosos. Partes laterais do protórax com sulco transversal próximo da borda anterior. Prosterno coberto por pubescência esbranquiçada. Metepisternos cobertos por pubescência alaranjada. Metasterno e urosternitos revestidos por pubescência esbranquiçada. Escutelo acastanhado com as bordas estreitamente amareladas.

Élitros com o quarto basal revestido por pubescência amarelo-alaranjada; segue-se faixa, antes do meio, de pubescência esbranquiçada que não toca a sutura; atrás do meio grande mancha de pubescência acastanhada, que não atinge a sutura, arredondada no limite anterior e irregular na borda posterior; quarto apical revestido por pubescência amarelo-alaranjada. Todo élitro com pontos contrastantes, os basais não são tuberculados.

Profêmures com pubescência esbranquiçada. Meso- e metafêmures cobertos por pubescência esbranquiçada, menos em grande mancha acastanhada no centro do lado externo. Meso- e metatíbias com pubescência esbranquiçada e pequenos pontos contrastantes; lado externo das mesotíbias coberto por pubescência acastanhada.

Dimensões em mm, holótipo fêmea. Comprimento total, 12,4; comprimento do protórax, 2,0; maior largura do protórax, 3,1; comprimento do élitro, 9,3; largura umeral, 4,7 .

Material-tipo. Holótipo fêmea, BRASIL, Piauí: Caracol (Parque Nacional da Serra das Confusões, Fonte dos Bois, 4329,391'S, $09^{\circ} 13,228^{\prime} \mathrm{W}, 587 \mathrm{~m}$ ), ㅇ, 7-17.XII.2010, A. M. SilvaNeto \& M. Xavier col.

Discussão. Oncioderes foi estabelecido por Martins \& Galileo (1990) para conter duas espécies: O. picta Martins \& Galileo, 1990, de São Paulo e $O$. rondoniae Martins \& Galileo, 1990 originalmente descrita de Rondônia. O. piauiensis sp. nov. distinguese de $O$. picta pelo padrão de colorido dos élitros, com mancha castanha nítida depois do meio precedida por faixa branca; de $O$. rondoniae difere pelo vértice com duas pequenas manchas triangulares de pubescência castanha e atrás dos olhos com pubescência alaranjada; pela pubescência pronotal esbranquiçada no meio e mais alaranjada para os lados.

\section{Compsosomatini}

\section{Brasiliosoma tibiale (Breuning, 1948)}

Phrynosoma tibiale BREUnING, 1948:3.

Brasiliosoma tibialis; BREUNING, 1960:181.

Brasiliosoma tibiale; MoNNÉ, 1980:44, fig. 10; MONNÉ, 2005 b:362 (cat.).

Material examinado. BRASIL, Bahia: Pindobaçu (Cachoeira da Fumaça, $\left.10^{\circ} 28^{\prime} 43^{\prime \prime} \mathrm{S}, 40^{\circ} 12^{\prime} 27,6^{\prime \prime} \mathrm{W}\right)$, + , 17.XII.2009, T. Zacca col. (novo registro).

\section{Laraesima ochreoapicalis Breuning, 1973}

Laraesima ochreoapicalis BREUnING, 1973:664; MoNNÉ 2005b:367 (cat.).

Material examinado. BRASIL, Paraíba: Areia (Reserva Pau

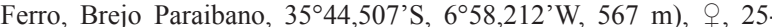
29.IX.2010, A. M. Silva-Neto \& F. E. Nascimento col., armadilha luminosa. (novo registro).

\section{Pteropliini}

\section{Ataxia parva Galileo \& Martins, 2011}

Ataxia parva Galileo \& Martins, 2011:179.

Material examinado. BRASIL, Ceará: Crato (Chapada do Araripe, $7^{\circ} 12,548^{\prime} \mathrm{S}, 39^{\circ} 35,839^{\prime} \mathrm{W}, 929 \mathrm{~m}$ ), ồ. A. M. Silva-Neto, M. X. Araújo \& E. Menezes col. (novo registro).

\section{Ataxia arenaria sp. nov.}

(Fig. 4)

Etimologia. Latim, arenaria $=$ de areia, alusivo à localidade-tipo.

Macho. Cabeça com tegumento castanho-escuro, coberta por pubescência amarelada, densa, que oblitera o tegumento. Vértice com o mesmo tipo de pubescência. Lobos oculares superiores estreitos, com três fileiras de omatídios, tão distantes entre si quanto o sêxtuplo da largura de um lobo e separados dos inferiores por única fileira de omatídios. Lobos oculares inferiores tão longos quanto as genas. Antenas alcançam aproximadamente o ápice dos élitros. Escapo coberto por pubescência amarelada, com a cicatriz apical pouco nítida. Flagelômeros cobertos por pubescência amarelada, os mais distais com anel apical preto.

Protórax apenas mais largo do que longo. Pronoto revestido por pubescência amarelada, com pouquíssimos pontos pequenos, entremeados e situados na metade basal. Partes laterais do protórax ligeiramente gibosas perto do meio.

Élitros cobertos por pubescência amarelada. Extremidades elitrais com espinho nítido no lado externo.

Fêmures revestidos por pubescência amarelada. Pro- e mesotíbias com pubescência amarelada. Metatíbias com tegumento preto, fortemente engrossadas e esparsamente pubescentes. Lado ventral do corpo revestido por pubescência amarelada. 
Dimensões em mm, holótipo macho. Comprimento total, 7,9; comprimento do protórax, 1,5; maior largura do protórax, 1,7; comprimento do élitro, 5,7; largura umeral, 1,9.

Material-tipo. Holótipo macho, BRASIL, Paraíba: Areia (Reserva Pau Ferro, Brejo Paraibano, 3544'507'S, 658'212'W, 567 m), 25-29.IX.2010, A. M. Silva-Neto \& F. E. Nascimento col., armadilha luminosa.

Discussão. Ataxia arenaria sp. nov., pelas pequenas dimensões e colorido geral uniformemente amarelado, assemelha-se a A. parva Galileo \& Martins 2011 e A. piauiensis Martins \& Galileo 2012. Distinguese de A. parva: pela ausência de faixa preta, sutural, na metade anterior dos élitros e pelas extremidades elitrais com espinho longo no lado externo. Em $A$. parva existe faixa preta, sutural, na metade anterior dos élitros e as extremidades elitrais são obliquamente truncadas. Difere de A. piauiensis pelos lobos oculares superiores estreitíssimos, pelo pronoto praticamente sem pontos, pelos élitros com pubescência uniforme e pelas extremidades elitrais espinhosas. Em $A$. piauiensis os lobos oculares têm quatro fileiras de omatídios, o pronoto é pontuado, a pilosidade elitral tem intervalos glabros e as extremidades elitrais são arredondadas e desarmadas.

\section{Desmiphorini}

\section{Ceiupaba lineata Martins \& Galileo, 1998}

Ceiupaba lineata Martins \& Galileo, 1998b:261, fig. 5; Monné, 2005b:380 (cat.).

Material examinado. BRASIL, Piauí: Caracol (Parque Nacional da Serra das Confusões, Fonte dos Bois, 4329,391'S, $09^{\circ} 13,228^{\prime} \mathrm{W}, 587 \mathrm{~m}$ ), ô, 7-17.XII.2010, A. M. Silva-Neto \& M. Xavier col. (novo registro).

\section{Cicuiara striata (Bates, 1866)}

Exocentrus striatus Bates, 1866:191.

Cosmotomidius? striatus; GiLmour, 1965:594 (cat.).

Cicuiara stritata; Galileo \& Martins, 1996a:875, fig. 5; Monné, 2005b:381 (cat.).

Material examinado. BRASIL, Piauí: Caracol (Parque

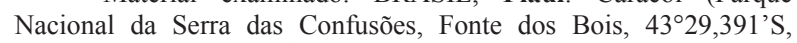
09¹3,228’W, 587 m), đ̊, 2 ㅇ, 7-17.XII.2010, A. M. Silva-Neto \& M. Xavier col. (novo registro).

\section{Desmiphora (Desmiphora) cirrosa Erichson, 1847}

Desmiphora cirrosa ERICHSON, 1847:147.

Desmiphora similis Breuning, 1943:46.

Desmiphora (Desmiphora) similis; Breuning, 1974:146; Monné \& Giesbert, 1994 (sin.)

Desmiphora (Desmiphora) cirrosa; Breuning, 1974:145, fig. 16; MONNÉ, 2005b:384 (cat.)

Material examinado. BRASIL, Ceará: Ubajara (Chapada de

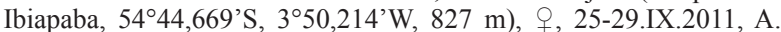
M. Silva-Neto \& F. E. Nascimento col., armadilha luminosa (novo registro).

\section{Desmiphora (Desmiphora) pallida Bates, 1874}

Desmiphora pallida BATES, 1874:226.

Desmophora pallida; LAMEere, 1883:62 (cat.).

Desmiphora grisea Aurivillius, 1904:208; Breuning, 1974:156 (sin).

Desmiphora (Desmiphora) pallida; Breuning, 1974:156; Monné, 2005b:384 (cat.).

Material examinado. BRASIL, Piauí: Caracol (Parque Nacional da Serra das Confusões, Fonte dos Bois, $43^{\circ} 29,391^{\prime} \mathrm{S}$, $09^{\circ} 13,228^{\prime} \mathrm{W}, 587 \mathrm{~m}$ ), , 7-17.XII.2010, A. M. Silva-Neto \& M. Xavier col. (novo registro).

\section{Cotycicuiara caracolensis sp. nov.}

(Fig. 5)

Etimologia. Nome específico alusivo à localidadetipo.

Macho. Tegumento preto. Cabeça coberta por pubescência acinzentada. Fronte estreita; sutura frontal continuada pela coronal, bem demarcadas. Lobos oculares superiores com sete fileiras de omatídios, mais próximos entre si do que largura de um lobo. Antenas atingem a extremidade dos élitros aproximadamente no ápice do antenômero VIII. Escapo e pedicelo pretos. Antenômeros III-XI preto-avermelhados com extremidades pretas.

Protórax revestido por pubescência acinzentada. Pronoto com pontos grossos e contrastantes menos nos tubérculos laterais. Metade superior das partes laterais do protórax pontuada. Metasterno com duas manchas pequenas, subcirculares, próximas do meio e da margem posterior.

Élitros revestidos por pubescência acinzentada no sexto basal e branca no restante da superfície; em cada élitro: duas manchas de pubescência castanha, subcirculares, atrás de meio, uma dorsal mais posterior e uma perto da margem; faixa de pubescência castanha, com limites irregulares antes do ápice. Pontos elitrais contrastantes com a pubescência esbranquiçada, maiores na parte central e gradativamente mais esparsos em direção ao ápice e ausentes na região anteapical.

Pernas cobertas por pubescência acinzentada.

Urosternitos com mancha indistinta de pubescência castanha nos lados.

Dimensões em mm, holótipo macho. Comprimento total, 8,9 ; comprimento do protórax, 1,7; maior largura do protórax, 2,5; comprimento do élitro, 6,3; largura umeral, 3,3.

Material-tipo. Holótipo macho, BRASIL, Piauí, Caracol (Parque Nacional da Serra das Confusões, Fonte dos Bois, $\left.43^{\circ} 29,391^{\prime} \mathrm{S}, 09^{\circ} 13,228^{\prime} \mathrm{W}, 587 \mathrm{~m}\right)$, ㅇ, 7-17.XII.2010, A. M. SilvaNeto \& M. Xavier col.

Discussão. O padrão de colorido de Cotycicuiara caracolensis sp. nov. assemelha-se ao de C. multicava Martins \& Galileo, 2010. Difere: pelo pronoto abundantemente pontuado; pela na base dos élitros com pubescência acinzentada e pelas manchas acastanhadas 

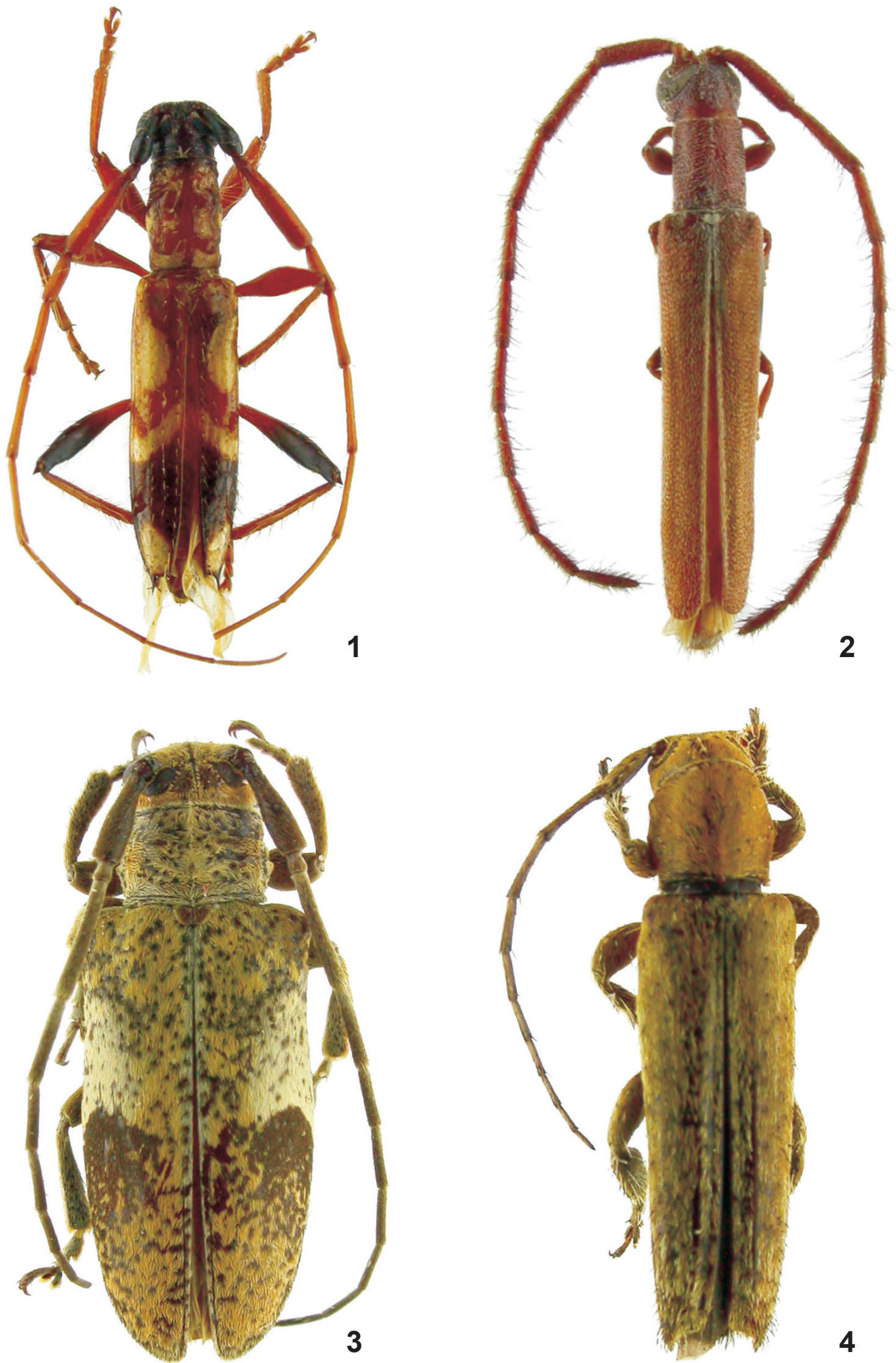

Figs 1-4: 1, Compsibidion paragraphycum sp. nov., holótipo macho, comprimento 10,3 mm; 2, Trichohippopsis vestita sp. nov., holótipo fêmea, comprimento $9,7 \mathrm{~mm} ; 3$, Oncioderes piauiensis sp. nov., holótipo fêmea, comprimento 12,4 mm; 4, Ataxia arenaria sp. nov., holótipo macho, comprimento $7,9 \mathrm{~mm}$. 
e arredondadas atrás do meio e pela faixa antes do ápice. Em C. multicava a pontuação do pronoto está restrita à declividade basal, à base dos élitros e atrás do meio com faixa transversal de pubescência acastanhada.

\section{Xenofreini}

\section{Xenofrea peculiaris sp nov.}

(Fig. 6)

Etimologia. Do Latim, peculiaris = peculiar, particular; alusivo à conformação do metasterno diferente das espécies conhecidas do gênero.

Macho. Tegumento corporal preto-avermelhado. Cabeça coberta por pubescência esbranquiçada com intromissão de pubescência amarelada ao redor dos olhos. Lobos oculares superiores com oito fileiras de omatídios, tão distantes entre si quanto à largura de um lobo. Antenas atingem as extremidades dos élitros aproximadamente no ápice do antenômero IX. Escapo castanho-avermelhado, estreitado na base e fusiformealongado no restante, coberto por pubescência esbranquiçada e esparsa; extremidade alcança o terço anterior do protórax. Antenômeros III a X castanhoavermelhados com a metade basal avermelhada. Antenômero XI com $3 / 4$ do comprimento do X.

Protórax mais largo do que longo; lados com tubérculo central e gibosidade pouco notável junto à borda anterior. Depressão anterior do pronoto coberta por pubescência amarelada; restante da superfície pronotal com pubescência branca, esparsa e áreas glabras entremeadas. Partes laterais do protórax com pubescência branca esparsa e áreas entremeadas glabras. Processo prosternal coberto por pubescência branca. Metepimeros com pubescência amarelada nos dois terços anteriores e pubescência branca no restante. Metasterno deprimido, com pubescência branca e escassa pubescência amarelada nos lados e duas manchas arredondadas de pubescência preta próximas da margem posterior. Escutelo com escassa pubescência amarelada.

Élitros com duas manchas pretas, arredondadas e pequenas no local da crista centro-basal, circundadas em pequena extensão, por pubescência amarelada e branca. Segue-se faixa glabra, oblíqua em sentido descendente da margem para a sutura, atrás dela uma faixa oblíqua, estreita de pubescência branca situada no meio do élitro; outra área glabra localizada mais para o lado da margem que não toca a sutura; mancha sutural, longitudinal, de pubescência branca; para os lados, uma faixa desnuda em forma de "M" onde também se vê uma elevação para o lado da margem; dessa elevação para o ápice, os élitros sofrem um estreitamento acentuado e estão cobertos por pubescência branca entremeada por duas pequenas manchas pretas.

Pernas revestidas por pubescência branca. Profêmures com tegumento preto e avermelhado no pedúnculo.
Urosternitos I-IV com pubescência amarelada na margem posterior. Urosternito $\mathrm{V}$ com pubescência branca.

Dimensões em mm, holótipo macho. Comprimento total, 6,0; comprimento do protórax, 1,2; maior largura do protórax, 1,8; comprimento do élitro, 4,2; largura umeral, 2,2 .

Material-tipo. Holótipo macho, BRASIL, Piauí, Caracol (Parque Nacional da Serra das Confusões, Fonte dos Bois, $43^{\circ} 29,391^{\prime} \mathrm{S}, 09^{\circ} 13,228^{\prime} \mathrm{W}, 587 \mathrm{~m}$ ), ㅇ, 7-17.XII.2010, A. M. SilvaNeto \& M. Xavier col.

Discussão. Xenofrea peculiaris sp. nov. tem duas manchas circulares, pequenas, dorsais na base dos élitros e metasterno bem aprofundado, caracteres que não se encontram nas demais espécies do gênero.

\section{Acanthoderini}

\section{Nesozineus apharus Galileo \& Martins, 1996}

Nesozineus apharus Galileo \& Martins, 1996b:43, fig. 2; Monné, 2005b:182 (cat.).

Material examinado. BRASIL, Piauí: Caracol (Parque Nacional da Serra das Confusões, Fonte dos Bois, 43²9,391'S, $\left.09^{\circ} 13,228^{\prime} \mathrm{W}, 587 \mathrm{~m}\right)$, ๙ै, 7-17.XII.2010, A. M. Silva-Neto \& M. Xavier col. (novo registro).

\section{Psapharochrus itatiayensis (Melzer, 1935)}

Acanthoderes itatiayensis Melzer, 1935:194.

Acanthoderes (Psapharochrus) itatiayensis; GILMOUR, 1965:615 (cat.) Psapharochrus itatiayensis; MonNé, 2005 b:205 (cat.).

Material examinado. BRASIL, Paraíba: Areia (Reserva Pau

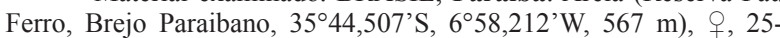
29.IX.2010, A. M. Silva-Neto \& F. E. Nascimento col., armadilha luminosa (novo registro).

\section{Psapharochrus nigrovittatus (Zajciw, 1969)}

Acanthoderes nigrovittata ZAJCIW, 1969:109, fig. 1.

Acanthoderes (Psapharochrus) nigrovittata; Monné, 1994:66 (cat.). Psapharochrus nigrovittatus; MonNÉ, 2005b:210 (cat.).

Material examinado. BRASIL, Piauí: Caracol (Parque Nacional da Serra das Confusões, Fonte dos Bois, 43²9,391'S, 09¹3,228’W, 587 m), \&, 7-17.XII.2010, A. M. Silva-Neto \& M. Xavier col. (novo registro).

\section{Hemilophini}

\section{Adesmus hemispilus (Germar, 1821)}

Saperda hemispila GERMAR, 1821:169.

Amphyonica hemispila; THOMsOn, 1857:311.

Amphionycha hemispila; REDTENBACHER, 1867:187 (distr.).

Hemilophus hemispilus; Gemminger \& Harold, 1873:3209 (cat.).

Saperda luctuosa Audinet-SERVILle, 1835:46.

Hemilophus luctuosus; LAPORTE, 1840:488.

Adesmus hemispilus; Aurivillius, 1923:589 (cat.); MonNÉ, 2005b:444 (cat.)

Material examinado. BRASIL, Bahia: Santa Terezinha (Serra da Gibóia), 9, 29.XI.2008, T. Zacca \& E. Alvim col. (novo registro). 


\section{Mariliana bellula sp. nov.}

(Fig. 7)

Etimologia. Latim, bellula $=$ diminutivo de bellus, bonito, alusivo ao colorido inusitado.

Fêmea. Tegumento preto. Fronte revestida por pubescência branca, com mancha triangular de pubescência alaranjada. Vértice coberto por pubescência alaranjada.

Antenas pretas. Flagelômeros com pelos longos no lado interno.

Pronoto coberto na metade anterior por pubescência alaranjada; metade posterior com uma mancha branca de cada lado, colada na margem basal e circundada por preto. Partes laterais do protórax com duas manchas de pubescência branca circundadas de preto. Prosterno com pubescência branca. Escutelo coberto por pubescência branca.

Élitros com pubescência alaranjada, cada um com cinco manchas subarredondadas, de pubescência branca, circundadas por preta: (1) soldada à base, dorsal, ao lado do escutelo; (2) no terço anterior, dorsal, aproximada da sutura e com a borda preta unida à borda da mancha central; (3) no meio, também dorsal; (4) no terço apical, a maior de todas, dorsal; (5) nas extremidades.

Fêmures pretos com mancha de pubescência branca no lado dorsal. Tíbias e tarsos pretos.

Face ventral do corpo preta com pubescência branca: mesosterno; mesepisternos; mesepimeros; metade apical dos metepisternos; lados do metasterno e dos urosternitos I-III.

Dimensões em mm, holótipo fêmea. Comprimento total, 8,8 ; comprimento do protórax, 1,8; maior largura do protórax, 1,8; comprimento do élitro, 6,2; largura umeral, 2,2 .

Material-tipo. Holótipo fêmea, BRASIL, Piauí, Caracol (Parque Nacional da Serra das Confusões, Fonte dos Bois, 43⒉29,391'S, 09¹3,228”W, 587 m), 7-17.XII.2010, A. M. Silva-Neto \& M. Xavier col.

Discussão. Mariliana bellula sp. nov. assemelhase a $M$. ocularis (Hope, 1846), mas difere: pela fronte revestida por pubescência branca; pela base do pronoto sem mancha de pubescência branca adiante do escutelo; pela presença das manchas de pubescência branca na base dos élitros; pelas áreas pretas que circundam as manchas de pubescência branca no meio dos élitros fundidas. Em M. ocularis: a fronte é revestida por pubescência alaranjada; a base do pronoto tem mancha de pubescência branca adiante do escutelo e uma a cada lado; a base dos élitros não tem manchas de pubescência branca; pelas áreas pretas que circundam as manchas de pubescência branca da região central dos élitros distantes entre si.

\section{Dadoychus atrus sp. nov.}

(Fig. 8)

Etimologia. Latim, atrum = preto; alusivo ao colorido dos élitros.

Fêmea. Cabeça com tegumento preto; fronte coberta por pubescência amarelo- alaranjada; genas com pubescência branca; vértice com uma faixa de pubescência amarelo-alaranjada entre os lobos oculares superiores e bifurcada para trás. Antenas aproximam-se do ápice dos élitros, mas não chegam a atingi-los. Escapo preto. Pedicelo preto com anel basal avermelhado. Antenômero III preto com base amarelada, gradualmente e pouco engrossado para o ápice; comprimento um terço maior que o escapo e o antenômero IV; pelos pretos, curtos em toda superfície e franja curta no lado interno. Antenômeros IV e V com tegumento amarelado, VI e VII pretos com anel basal amarelado. Antenômeros VIII-XI pretos.

Lados do protórax com gibosidade; partes laterais pretas com pontos esparsos. Pronoto convexo, preto com os lados cobertos por pubescência amarelo-alaranjada em continuação às faixas da cabeça. Prosterno com pubescência branca. Escutelo preto.

Élitros pretos, exceto úmeros com tegumento amarelado em pequena extensão e que é continuação das faixas pronotais. Extremidades elitrais arredondadas.

Fêmures avermelhados e escurecidos na extremidade. Face ventral do corpo preta.

Dimensões em $\mathrm{mm}$, holótipo fêmea/parátipo fêmea. Comprimento total, 8,0/8,3; comprimento do protórax, 1,3/1,4; maior largura do protórax, 2,1/1,9; comprimento do élitro, 6,0/6,2; largura umeral, 2,4/2,3.

Material-tipo. Holótipo fêmea, BRASIL, Paraíba: Areia (Reserva Pau Ferro, Brejo Paraibano, 3544,507'S, 658,212'W, 567 m), 25-29.IX.2010, A. M. Silva-Neto \& F. E. Nascimento col., armadilha luminosa. Parátipo fêmea, com mesmos dados do holótipo.

Discussão. Dadoychus Chevrolat, 1833 estava composto por três espécies: D. flavocinctus Chevrolat, 1833, espécie-tipo do gênero, descrita do Brasil; D. mucuim Galileo \& Martins, 1998, conhecida de Pernambuco e Ceará e D. nigrus Galileo \& Martins, 2009, descrita da Bahia. A descoberta de mais uma espécie do nordeste do Brasil, D. atrus sp. nov., sugere que a distribuição das espécies esteja relacionada com plantas do nordeste do Brasil.

Dadoychus atrus sp. nov. distingue-se de $D$. flavocinctus: pela sutura e margens dos élitros pretas, pelos antenômeros IV e V com tegumento amarelado e pelos urosternitos pretos. Em D. flavocinctus a sutura elitral e as margens dos élitros são amareladas, as antenas são pretas, sem antenômeros claros e os urosternitos III e IV são cobertos por pubescência esbranquiçada. D. atrus separa-se de D. mucuim: pelas faixas de pubescência amarelada dos lados do 

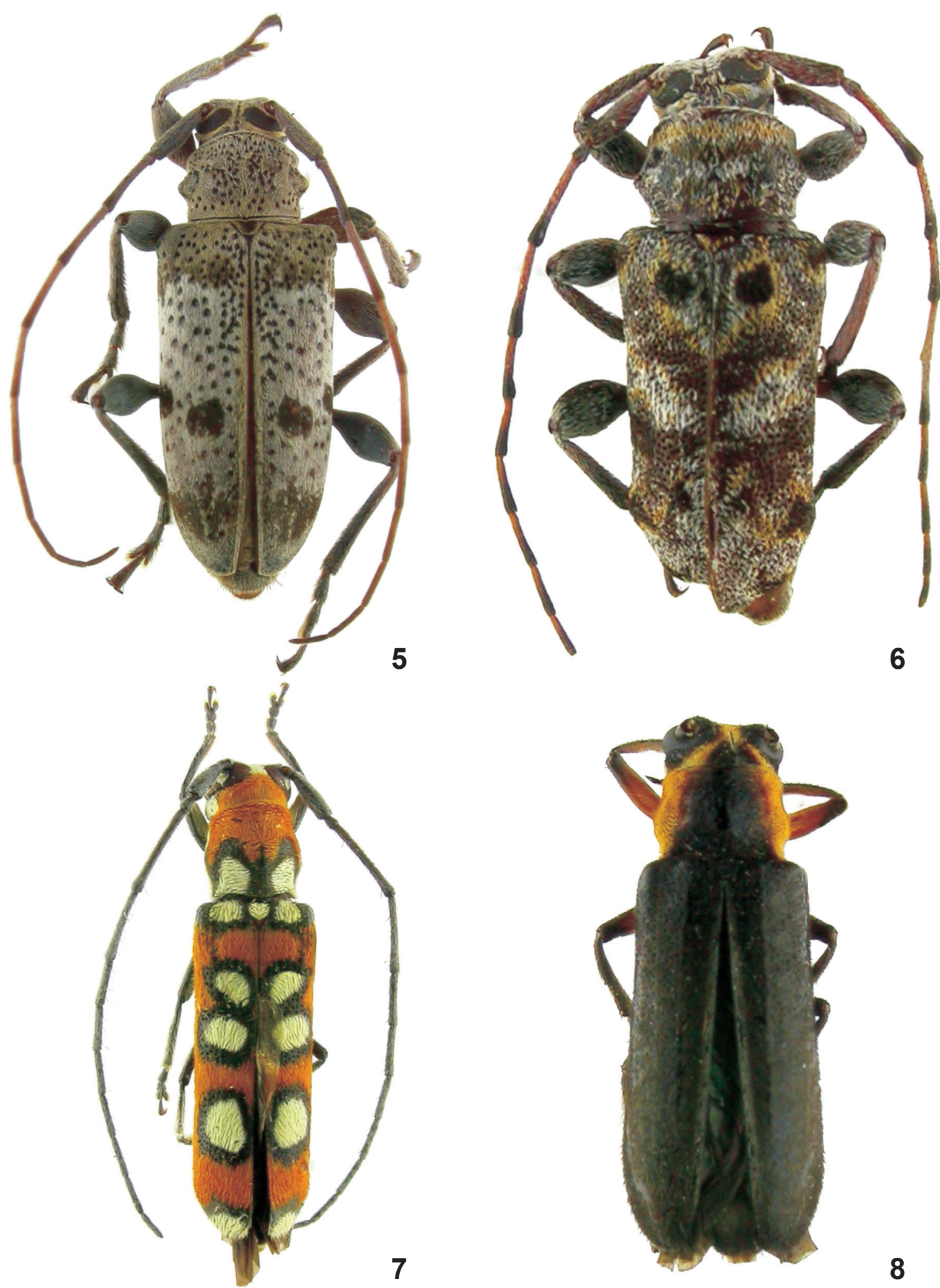

8

Figs 5-8: 5, Cotycicuiara caracolensis sp. nov., holótipo macho, comprimento $8,9 \mathrm{~mm}$; 6, Xenofrea peculiaris sp. nov., holótipo macho, comprimento 6,0; 7, Mariliana bellula sp. nov., holótipo fêmea, comprimento $8,8 \mathrm{~mm} ; 8$, Dadoychus atrus sp. nov., holótipo fêmea, comprimento 8,0 . 
pronoto mais estreitas; pelas epipleuras com tegumento amarelado só em curta extensão basal. Em D. mucuim as faixas de pubescência amarelada dos lados do pronoto são muito mais largas e ocupam quase a superfície total do pronoto e as epipleuras são amareladas nos $3 / 4$ basais. Dadoychus atrus sp. nov. difere de D. nigrus pelas faixas de pubescência amarelada dos lados do pronoto.

\section{Aerenicini}

\section{Aereniphaula machadorum Galileo \& Martins, 1990}

Aereniphaula machadorum GALILEO \& MARTIns, 1990:584, fig. 2; Monné, 2005b:228 (cat.)

Material examinado. BRASIL, Piauí: Caracol (Parque Nacional da Serra das Confusões, Fonte dos Bois, 4329,391'S, $\left.09^{\circ} 13,228^{\prime} \mathrm{W}, 587 \mathrm{~m}\right)$, +, 7-17.XII.2010, A. M. Silva-Neto \& M. Xavier col. (novo registro).

\section{Antodice lenticula Martins \& Galileo, 1985}

Antodice lenticula Martins \& Galileo, 1985:92, fig. 7; Monné, 2005b:241 (cat.)

Material examinado. BRASIL, Piauí: Caracol (Parque Nacional da Serra das Confusões, Fonte dos Bois, 4329,391'S, 09¹3,228'W, $587 \mathrm{~m}$ ), ô, 7-17.XII.2010, A. M. Silva-Neto \& M. Xavier col. (novo registro).

\section{Recchia abauna Martins \& Galileo, 1998}

Recchia abauna Martins \& Galileo, 1998a:71, fig. 51; Monné, 2005b:230 (cat.)

Material examinado. BRASIL, Ceará: Crato (Chapada do Araripe, $7^{\circ} 12,548^{\prime} \mathrm{S}, 39^{\circ} 35,839^{\prime} \mathrm{W}, 929$ m), ồ, A. M. Silva-Neto, M. $\mathrm{X}$. Araújo \& E. Menezes col. (novo registro)

Agradecimentos. A Freddy Rubem Bravo Quijano e Francisco Eriberto (Museu de Zoologia da Universidade Estadual de Feira de Santana, Bahia), pela remessa de material para estudo; a Antonio Santos Silva (MZSP) pela execução das imagens.

\section{REFERÊNCIAS BIBLIOGRÁFICAS}

Audinet-Serville, J. G. 1835. Nouvelle classification de la famille des longicornes (suite). Annales de la Société Entomologique de France 4:5-100

Aurivillius, C. 1904. Cerambyciden aus Bolivien und Argentina gesammelt von Freiherrn Erland Nordenskiöld. Entomologisk Tidskrift 25:205-208.

. 1923. Coleopterorum Catalogus, pars 74, Cerambycidae: Lamiinae. II. Berlin, W. Junk, p. 323-704.

Bates, H. W. 1865. Contributions to an insect fauna of the Amazon Valley. Coleoptera: Longicornes. The Annals and Magazine of Natural History 16:167-182.

1866. Contributions to an insect fauna of the Amazon Valley. Coleoptera: Longicornes. The Annals and Magazine of Natural History 17:191-202.

1870. Contributions to an insect fauna of the Amazon Valley. The Transactions of the Entomological Society of London 1870:243-335.

1874. Supplement to the longicorn Coleoptera of Chontales, Nicaragua. The Transactions of the Entomological Society of London 1874:219-235.
Breuning, S. 1942. Novae species Cerambycidarum. XI. Folia Zoologica et Hydrobiologica 11:113-175.

1943. Novae species Cerambycidarum. XII. Folia Zoologica et Hydrobiologica 12:12-66.

1948. Nouvelles formes de Lamiaires (Première partie) Bulletin du Muséum d'Histoire Naturelle de Belgique 24(38): 1-44.

1958. Nouvelles formes de Lamiaires (Dixième partie) Bulletin du Institut des Sciences Naturelles de Belgique 34(22):1-47.

1960. Catalogue des Lamiaires du Monde(Col., Cerambycidae)

3 Lief. Museum G. Frey, Tutzing bei München, p. 109-182.

1973. Lamiaires nouveaux ou peu connus du Muséum de Paris (Col., Cerambycidae). Annales de la Société Entomologique de France (n.s.) 9(3):647-665.

Révision des Rhodopinini américains. Studia Entomologica 17(1-4):1-210.

BuQueT, M. L. 1860. Description de quelques longicornes nouveaux. Annales de la Société Entomologique de France 8:617-628.

ERICHSON, W. F. 1847. Conspectus insectorum coleopterorum quae in Republica Peruana observata sunt. Archiv für Naturgeschichte 13:67-185.

Galileo, M. H. M. \& Martins, U. R. 1990. Aditamentos à tribo Aerenicini (Coleoptera, Cerambycidae, Lamiinae). Revista Brasileira de Entomologia 34:583-588.

1996a. Notas e descrições em Desmiphorini (Coleoptera, Cerambycidae, Lamiinae), com uma revisão do gênero Mimasyngenes Breuning. Revista Brasileira de Zoologia 13(4):867-882.

1996b. Revisão do gênero Nesozineus Linsley \& Chemsak, 1966 (Coleoptera, Cerambycidae, Lamiinae, Acanthoderini). Revista Brasileira de Entomologia 40(1):41-46.

2011. Novas espécies de Acanthoderini, Onciderini e Pteropliini (Coleoptera: Cerambycidae: Lamiinae) do Brasil e da Bolívia. Acta Amazonica 41(1):175-182.

Gemminger, M. \& Harold, E. von. 1873. Catalogus Coleopterorum hucusque descriptorum synonymicus et systematicus. v.10 p.2989-3232.

Germar, E. F. 1821. Neue exotische Käfer beschrieben von C. R. W. Wiedemann u. E. F. Germar. Magazin der Entomologie 4:107-183.

Gilmour, E. F. 1965. Catalogue des Lamiaires du Monde. 8 Lief. Tutzing b. München, Mus. G. Frey, p. 559-655.

Gounelle, E. 1909a. Liste des cérambycides de la région de Jatahy, Etat de Goyaz, Brésil (1ère partie). Annales de la Société Entomologique de France 77:587-688

1909b. Notes synonymiques (Col. Cerambycidae). Bulletin de la Société Entomologique de France 1909:304-305.

LAMEere, A. A. 1883. Liste des cérambycides, décrits postérieurement au catalogue de Munich. Annales de la Société Entomologique de Belgique 26:1-78.

LAPORTE, F. L. N. 1840. Histoire Naturelle des Insectes Coléoptères. Paris, P. Duménil, 2:1-563.

Lingafelter, S. W. The genera of Elaphidiini Thomson1864 (Coleoptera: Cerambycidae). Memoirs of the Entomological Society of Washington 20:1-118.

Martins, U. R.1962. Ibidionini XV. Novas espécies, notas sinonímicas, redescrições. Papéis Avulsos do Departamento de Zoologia 14(30):267-310

.1968. Monografia da tribo Ibidionini. Parte II. Arquivos de Zoologia 16(2):321-630.

1969. Monografia da tribo Ibidionini (Coleoptera Cerambycinae). Arquivos de Zoologia 16(3):631-877. 2005. Tribo Elaphidionini, 393 pp. In: Martins, U. R org. Cerambycidae sul-americanos (Coleoptera). Curitiba, Sociedade Brasileira de Entomologia. v. 7, 393p.

Martins, U. R. \& Galileo, M. H. M. 1985. Contribuição ao estudo da tribo Aerenicini (Coleoptera, Cerambycidae, Lamiinae). III Gêneros com lobos oculares superiores subcontíguos. Revista Brasileira de Entomologia 29(1):89-94.

1990. Onciderini (Coleoptera, Cerambycidae, Lamiinae) sinonímias, novos táxons, chaves e notas. Papéis Avulsos de Zoologia 37(4):53-95.

1997. Tribo Methiini, p.158-217. In: Martins, U. R. org Cerambycidae sul-americanos (Coleoptera). Curitiba Sociedade Brasileira de Entomologia. v.1, 257p. 
1998a Revisão da tribo Aerenicini Lacordaire, 1872 (Coleoptera, Cerambycidae, Lamiinae). Arquivos de Zoologia 35(1):1-133.

. 1998b. Gêneros sul-americanos de Desmiphorini (Coleoptera, Cerambycidae) com lados do protórax desarmados. Revista Brasileira de Entomologia 41(2-4):257-265.

2007. Tribo Ibidionini. Subtribo Ibidionina, p.177-330.

In: Martins, U. R. org. Cerambycidae sul-americanos (Coleoptera). Curitiba, Sociedade Brasileira de Entomologia. v.9, 349p.

2012. Seven new species of Cerambycidae (Coleoptera) from South America with the proposal of three new genera. Zoologia 29(6): 557-562.

Martins, U. R., Galileo, M. H. M. \& Limeira-de-Oliveira, F. 2009a. Cerambycidae (Coleoptera) do estado de Maranhão, Brasil I. Papéis Avulsos de Zoologia 49(19):229-247.

. 2009b. Cerambycidae (Coleoptera) do estado de Maranhão, Brasil II. Papéis Avulsos de Zoologia 49(38):503-527.

. 2011. Cerambycidae (Coleoptera) do estado do Maranhão, Brasil. III. Papéis Avulsos de Zoologia 51(18):275-293.

Martins, U. R. \& NAPP, D. S. 1983. Gêneros Stizocera Audinet Serville, Nesostizocera Linsley e Parastizocera Linsley: chaves para espécies, descrições, notas e sinonímias. Papéis Avulsos de Zoologia 35(7):79-92.

Melzer, J. 1935. Novos cerambycideos do Brasil, da Argentina e de Costa Rica. Archivos do Instituto de Biologia Vegetal 2(2):173205.

Monné, M. A. 1980. Contribuição ao conhecimento dos Compsosomatini (Coleoptera, Cerambycidae, Lamiinae). Parte I. Revista Brasileira de Entomologia 24(1):29-51.

Catalogue of the Cerambycidae (Coleoptera) of the Western Hemisphere. Part XVII. Subfamily Lamiinae: Tribes Anisocerini, Polyrhaphidini, Xenofreini, Acrocinini and Acanthoderini. São Paulo, Sociedade Brasileira de Entomologia. 110p.

. 2005a. Catalogue of the Cerambycidae (Coleoptera) of the Neotropical region. Part I. Subfamily Cerambycinae. Zootaxa 946:1-765.

2005b. Catalogue of the Cerambycidae (Coleoptera) of the Neotropical region. Part II. Subfamily Lamiinae. Zootaxa 1023:1-759.
Monné, M. A. \& Giesbert, E. F. 1994. Checklist of the Cerambycidae and Disteniidae (Coleoptera) of the Western Hemisphere. Wolfogarden, Burbank. xiv $+410 \mathrm{p}$.

Monné, M. A. \& Hovore, F. T. 2006. Checklist of the Cerambycidae, or longhorned wood-boring beetles, of the Western Hemisphere. Rancho Dominguez (CA), BioQuip. 394p.

NapP, D. S. 1993. Duas espécies novas do gênero Orthoschema A.Serville, 1834 (Coleoptera, Cerambycidae, Compsocerini). Revista Brasileira de Entomologia 37(4):653-656.

1994. Revisão do gênero Orthostoma Lepeletier \& A.Serville, 1830 e descrição de Aglaoschema, gen. n. (Coleoptera, Cerambycidae, Compsocerini). Revista Brasileira de Entomologia 38(3-4):645-660.

REDTENBACHER, L. 1867. Coleopteren. In: Reise des österreichischen Fregatte Novara und die Erde in den Jahren 1857, 1858, 1859, unter der befehlen des Commodore B. von WüllerstorfUrbair. Wien, Zoologischer Theil. Zweiter Band, 249p.

TaVAKILIAN, G. L. 1991. Notas sinonímicas e novas combinações em longicórneos sul-americanos (Coleoptera, Cerambycidae). Revista Brasileira de Entomologia 35(2):439-453.

Thomson, J. 1857. Description de cérambycides nouveaux ou peu connus de ma collection. Archives Entomologiques 1:291-320.

ZAJCIW, D. 1965. Contribuições para o estudo da fauna dos longicórneos do Estado da Paraíba (Coleoptera, Cerambycidae). Boletim da Sociedade Cearense de Agronomia 6:5-21.

1966. Contribuição para o estudo da fauna dos longicórneos do Estado do Ceará. (Coleoptera, Cerambycidae). Boletim da Sociedade Cearense de Agronomia 7:1-11.

1967. Contribuição para o estudo da fauna dos longicórneos do Estado do Maranhão (Col., Ceramb.). Boletim da Sociedade Cearense de Agronomia 8:1-12.

1968a. Contribuição para o estudo da fauna dos longicórneos do Nordeste brasileiro (Coleoptera, Cerambycidae). Revista Brasileira de Entomologia 13:119-130.

1968b. Primeiro suplemento à fauna dos longicórneos do Nordeste brasileiro (Coleoptera, Cerambycidae). Atas da Sociedade de Biologia 12(3):119-121.

1969. Uma nova espécie do gênero Acanthoderes Serville, 1835 (Coleoptera, Cerambycidae, Lamiinae). Anais da Academia Brasileira de Ciências 41(1):109-111. 